\title{
Protein and water recovery from poultry processing wastewater integrating microfiltration, ultrafiltration and vacuum membrane distillation
}

\author{
W. Białas $\cdot$ J. Stangierski $\cdot$ P. Konieczny
}

Received: 4 October 2012/Revised: 4 February 2014/Accepted: 13 March 2014/Published online: 10 April 2014

(C) Islamic Azad University (IAU) 2014

\begin{abstract}
A novel approach for the recovery of the proteins contained in the effluent formed during production of surimi-like material from mechanically recovered poultry meat was proposed, using an integrated membrane process comprising microfiltration, ultrafiltration and vacuum membrane distillation. Additionally, the possibility of using the integrated membrane process to achieve highquality water for reuse was also investigated. Using crossflow membrane techniques, it was found that the total recovery of soluble proteins as well as the average degree of concentration amounted to $84 \%$ and 9.3 , respectively. Moreover, using this process, the total recovery of water was $70 \%$ and the percentage reduction in COD, TOEM and TSS in the permeate obtained using vacuum membrane distillation exceeded $99 \%$. As a result, the water recovered by the integrated membrane process could be reused in the manufacture of surimi-like material from mechanically recovered poultry meat.
\end{abstract}

Keywords Water purification - Polypropylene membrane - Fouling · Rejection coefficient - Mechanically recovered poultry meat $\cdot$ Hydrophobicity $\cdot$ Downstream pressure

W. Białas $(\bowtie)$

Department of Biotechnology and Food Microbiology, Poznan University of Life Sciences, Wojska Polskiego 48, 60-627 Poznan, Poland

e-mail: wbialas@up.poznan.pl

J. Stangierski $\cdot$ P. Konieczny

Department of Food Quality Management, Poznan University of

Life Sciences, Wojska Polskiego 31, 60-624 Poznan, Poland

\section{Introduction}

In the recent years, there has been a significant increase in meat consumption, with the consumption of poultry increasing at an even faster rate than that of beef or pork. In the case of poultry, it will entail a considerable increase in the quantity of the less popular parts of the carcass, e.g., necks, backs and drumsticks. One of the methods enabling further use of these parts is the production of mechanically recovered poultry meat (MRPM), which may be used to produce sausages or canned meat (Hrynets et al. 2011; Pereira et al. 2011; Jin et al. 2007). Unfortunately, due to its high myoglobin and hemoglobin content, MRPM has worse functional properties than meat which is carved manually. It was shown that this material has undesired textural properties and sometimes an unpleasant odor due to the rancidity of fat (Hrynets et al. 2011). In order to improve the functional properties of this product, a technology was designed to enable the recovery of myofibrillar proteins, similar to the one used in the fishing industry to produce what is known as surimi. The technology consists in washing the product several times with sodium chloride solution to remove fat, soluble sarcoplasmic proteins and odorous substances and concentrate myofibrillar proteins (Froning and McKee 2001). Preparations achieved using this have outstanding gelling properties and a color similar to that of white poultry meat (Martín-Sánchez et al. 2009; Tina et al. 2010).

However, the technology of producing surimi-like material from poultry meat yields large amounts of process water which contains proteins, fats, dyes and numerous dissolved substances. In the fishing industry, the production of $1 \mathrm{~kg}$ of surimi from fish yields usually requires $20 \mathrm{~L}$ of water (Piyadhammaviboon and Yongsawatdigul 2009). It was found that a similar amount of water is used when 
producing surimi-like material from poultry yields. The resulting wastewater is a substantial financial burden for the poultry industry, as it needs to be initially purified before being discharged into the sewage system (William 2000). Therefore, new methods are still being developed to limit the use of water and the production of wastewater and to recover the proteins it contains (Lin and Jae 2005).

One of the methods of limiting the amount of wastewater and the use of water by almost two-thirds compared with the traditional method is the counter-current washing of MRPM (Lee 1990). Despite many possible economic benefits, the technology has yet to be used on an industrial scale (Lin and Jae 2005). Proteins can be removed from the process water by means of coagulation or flocculation $(\mathrm{Ng}$ et al. 1994; Xu et al. 2001; Sridhar et al. 2013). If the process water also includes large amounts of fat, integrated methods are recommended, including dissolved air flotation-flocculation (Tezel et al. 2007; Joe and Muhammad 2000) or membrane bioreactor (Khan et al. 2014). Unfortunately, the sarcoplasmic protein concentrate obtained in this way cannot be used in food production (Afonso and Bórquez 2002). It mostly results from the fact that both coagulants and flocculants, binding to proteins and causing their precipitation, modify their structure and, consequently, their functional properties. Moreover, the flocculants and coagulants used are toxic (Renault et al. 2009; Li et al. 2013; Bourtoom et al. 2009). It is, of course, possible to use biopolymers, such as alginate and chitosan, which are perfectly safe for health (Wibowo et al. 2005, 2007; Geetha Devi et al. 2012). However, the effectiveness of flocculants based on biopolymers is very often lower compared with synthetic polymers, as a result of which they are not profitable (Alan et al. 2005).

One alternative to the above-mentioned methods are pressure-driven membrane processes, such as microfiltration (MF), ultrafiltration (UF), nanofiltration (NF), and reverse osmosis (RO), which are used to recover proteins from palm oil mill effluent (Wu et al. 2007), wastewater from isolated soy protein production (Cassini et al. 2010), effluent from milk factories (Adams et al. 2013), fish and poultry processing wastewater (Afonso and Bórquez 2002; Diná Afonso et al. 2004; Lo et al. 2005; Avula et al. 2009; Lin et al. 1995). Their usefulness mostly stems from the relatively low capital expenditure necessary to launch the installation, the fact that their scale can be easily increased and the energy-efficient conditions of the process (Mohammad et al. 2012).

Unfortunately, the membrane processes inevitably entail fouling, which causes a dramatic drop in the efficiency of the separation, due to the accumulation of separated particles both on the surface and inside the pores of the membrane (Mohammad et al. 2012). Moreover, as a result of the complex composition of the process water, which apart of proteins contains fats and many other small-molecule substances, in order to achieve the purity of water which will enable its recycling, integrated processes must be used, such as UF/RO (Shelly and Glenn 2000; Bohdziewicz and Sroka 2005). Membranes used for RO make it possible to achieve a $90 \%$ reduction in COD and BOD, but they require significantly higher pressures compared with MF and UF and an adequate feed pretreatment. Moreover, the membranes are very susceptible to fouling and scaling, which occur especially at a high concentration (Herzberg et al. 2010). One alternative to RO may be vacuum membrane distillation (VMD), a process driven by the difference in vapor pressure of water across the membrane (Khayet and Matsuura 2011). The specific mechanism of the separation results in the retention of all the nonvolatile compounds, such as proteins, fats, dyes and inorganic salt ions. Membrane distillation was used, among others, for olive mill wastewater treatment (El-Abbassi et al. 2012) and whey protein concentration (Hausmann et al. 2014). However, to the best of our knowledge, there is no data on the possibility of using VMD to purify the wastewater produced by the poultry or fishing industry.

The aim of this publication is to compare the effectiveness of cleaning process water after the production of surimi-like material from MRPM using ultrafiltration and the integrated process comprising MF, UF and VMD. The effects of experimental variables, feed temperature and downstream pressure on the VMD performance were studied using the statistical design of experiments (DOE). Mathematical models for the VMD permeate process variables were developed based on regression techniques. Finally, optimization of VMD process was carried out using the desirability function approach to determine the optimum VMD operating conditions. This research was conducted at the Poznan University of Life Sciences (Poland), from November 2011 to February 2012.

\section{Materials and methods}

Preparation of the wash water from mechanically recovered poultry meat

The basic research material was mechanically recovered meat from broiler carcasses without pectoral muscles and legs, produced by Lima RM 500 (Lima S.A.S.; Quimper, France), France. The temperature of the mechanically recovered poultry meat (MRPM) directly after the separation did not exceed $+6{ }^{\circ} \mathrm{C}$. The direct research material comprised myofibril preparation (MP) obtained from MRPM. The method of obtaining the preparation was based on the procedure described in the patent claim (Kijowski et al. 1996). The meat material was washed with a 
$1 \%$ aqueous solution of sodium chloride and then with running water (MRPM/water; 1:3; w/v). Fat and connective tissue were separated with the use of sieves. The production water from the first and second washings was mixed and placed in a cold store with a temperature of about $3{ }^{\circ} \mathrm{C}$. The material prepared in this way was analyzed further.

\section{Membrane separation}

In the first stage of the research, the proteins in the process water were separated using filtration on spiral-wound membranes with a cutoff of 3 and $30 \mathrm{kDa}$. Based on the results of the research, a UF membrane with an optimal cutoff was chosen. The membrane was selected on the basis of the filtrate stream retention coefficient for the total protein and a percentage reduction in COD, nitrogen, TOEM and TSS. The membrane was used in the second stage of the research, during which the process water was purified in an integrated system comprising MF, UF and
VMD. Pretreatment using microfiltration was used to remove suspensions from the process water. Ultrafiltration was used to separate soluble protein fractions, whereas VMD was used to obtain highly purified water, which may be used for the production of surimi-like material from MRPM.

Cross-flow microfiltration and ultrafiltration

The setup used to conduct the experiments of cross-flow microfiltration and ultrafiltration is presented in Fig. 1a. The MF pilot plant was equipped with a Prostak-open channel module with a $0.22 \mu \mathrm{m}$ Durapore ${ }^{\circledR}$ membrane (surface area $0.9 \mathrm{~m}^{2}$ ) supplied by Millipore (USA). The MF membrane was made of hydrophilic PVDF, which is highly resistant to many chemical substances and high temperature. The membrane was selected based on the literature, which shows that hydrophilic membranes reduce protein adsorption within membrane structures (Duclos-

$\mathbf{a}$

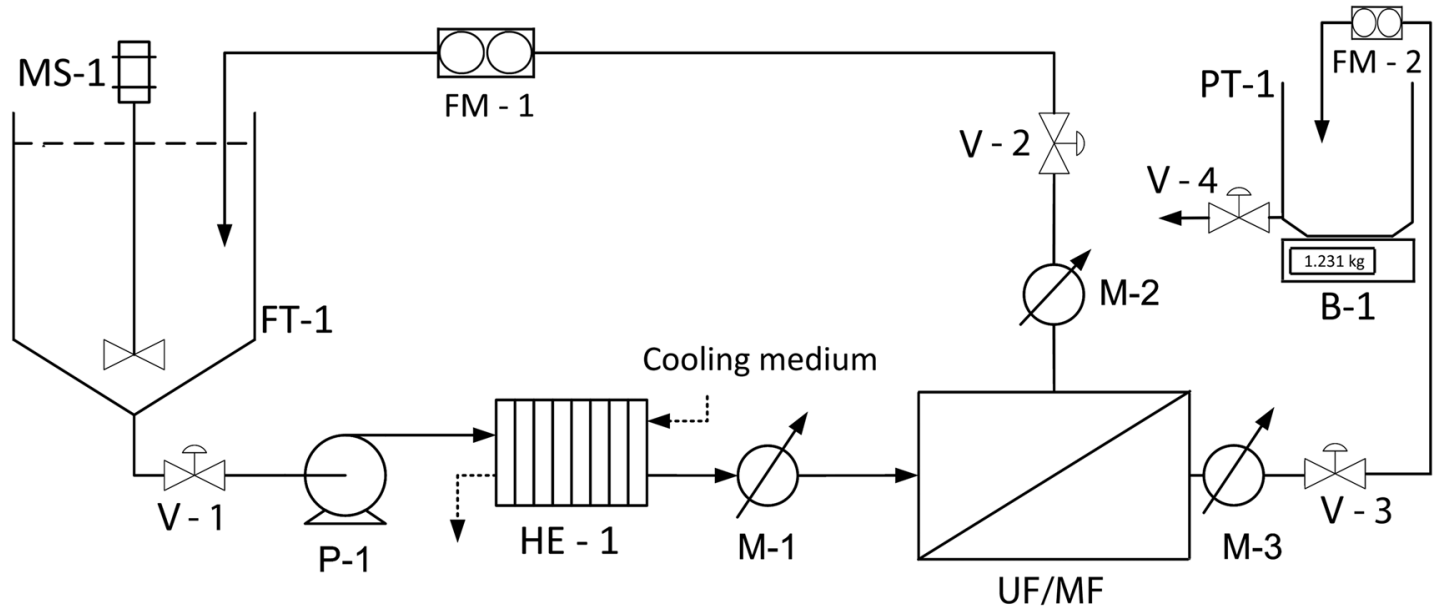

b

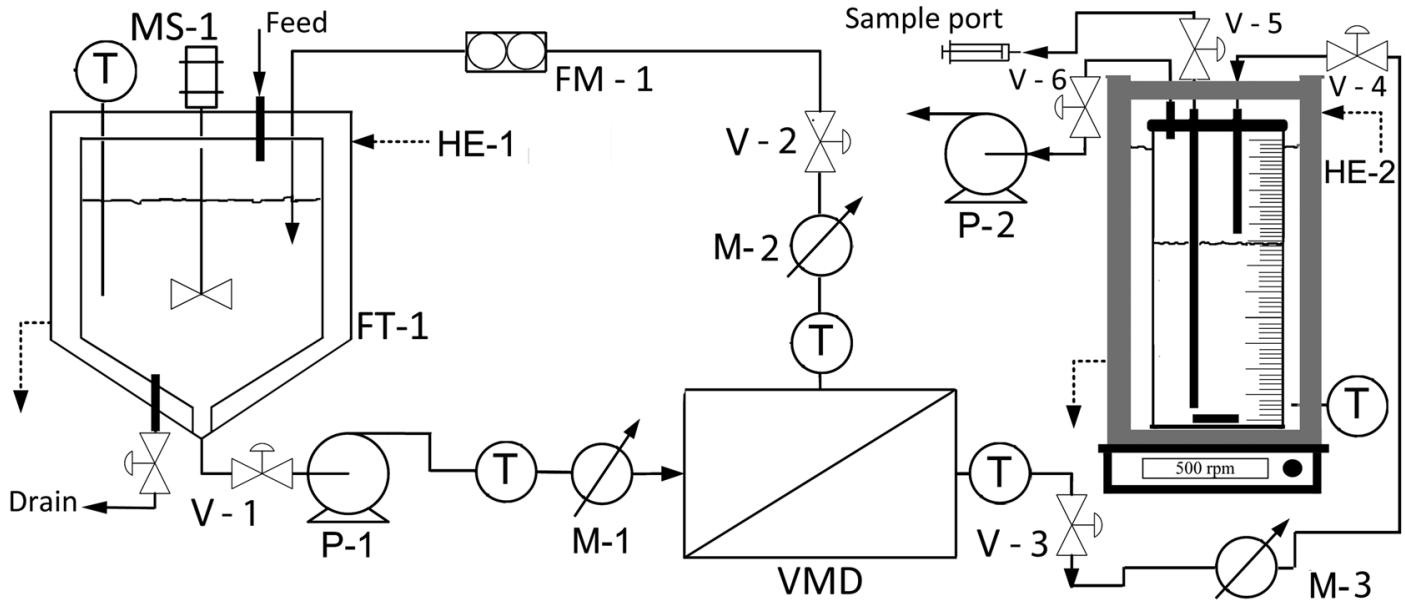

Fig. 1 Schematic diagram of the applied membrane separation systems: a micro and ultrafiltration and $\mathbf{b}$ vacuum membrane distillation. FT-1-feed tank, V-1-6-manual diaphragm valves, P-1, 2-pumps; HE-1, 2-heat exchangers; M-1, 2, 3-pressure sensors; MF/UF-microfiltration or ultrafiltration module; PT-1permeate tank; FM-1, 2-electromagnetic flowmeters; B-1-electronic balance; MS-1-mechanical stirrer, $T$-temperature sensors (Pt100) 
Orsello et al. 2006). It was assumed that this would limit the risk of membrane fouling. The MF system was operated at a TMP of $30 \pm 5 \mathrm{kPa}$, cross-flow velocity (CFV) of $2.0 \mathrm{~m} \mathrm{~s}^{-1}$ and temperature of $293.15 \mathrm{~K}$. The process was based on the batch concentration mode (recycling the retentate stream to the feed tank and collecting the permeate separately). After each experiment, the membrane was chemically cleaned in accordance with the manufacturer's recommendations. The system was first rinsed with water. It was then cleaned with a phosphoric acid solution $(10 \%$, $15 \mathrm{~min}$ ), and then rinsed to neutrality with distilled water. After each washing cycle, the membrane was tested with distilled water once again, in order to determine its hydraulic permeability.

Regenerated cellulose, spiral-wound ultrafiltration membranes (S10Y3, S10Y30 Amicon, USA) with a molecular weight cutoff of 3 and $30 \mathrm{kDa}$ and area of $0.92 \mathrm{~m}^{2}$ were tested for their ability to separate proteins from the poultry processing wastewater. The regenerated cellulose membrane ensures ultra-low protein binding and low fouling during use. Moreover, compared with other materials, such as polyethersulfone, the regenerated cellulose is the easiest to regenerate, with minimal cleaning water and no chemical treatment necessary (Dumay et al. 2008). The experiments were carried out in an open system, where the permeate was drained into a separate container (concentration mode). Concentration occurred at a TMP of $200 \pm 15 \mathrm{kPa}$ and cross-flow velocity inside the membrane of $2.5 \pm 0.2 \mathrm{~m} \mathrm{~s}^{-1}$. All the experiments were conducted at $293.15 \mathrm{~K}$. After each UF experiment, the membranes were first washed with distilled water, then with a $0.5 \mathrm{M}$ sodium hydroxide solution and finally again with distilled water. After each washing cycle, the membranes were tested with distilled water once again, in order to determine their hydraulic permeability.

Vacuum membrane distillation

Vacuum membrane distillation (VMD) experiments were performed by using a laboratory-scale setup equipped with a flat membrane module (membrane area of $0.0063 \mathrm{~m}^{2}$ ) supplied by Brocar (Poland, Fig. 1b). A flat-sheet hydrophobic, microporous membrane made of polypropylene (PP) with a pore size of $0.2 \mu \mathrm{m}$ and thickness of $170 \pm 15 \mu \mathrm{m}$ was tested (Membrana $\mathrm{GmbH}$, Germany). During the VMD experiments, the feed stream (the UF permeate) was heated in an insulated, jacketed stainless steel tank connected to the water circulator (Haake DC 10, Germany) and continuously fed by a peristaltic pump to the membrane module at a flow rate of $25.2 \mathrm{~L} \mathrm{~h}^{-1}\left(1.0 \mathrm{~m} \mathrm{~s}^{-1}\right)$. When the feed was heated to the desired temperature, a vacuum pump (PC 3001 Vario, Vaccubrand, Germany) was employed to vacuum at the permeate side. Due to the
Table 1 D-optimal experimental plan used to model and optimize VMD process

\begin{tabular}{lllc}
\hline Run & \multicolumn{2}{l}{ Independent variables } & \multicolumn{2}{l}{$\begin{array}{l}\text { Response } \\
\text { nynn}\end{array}$} & $\begin{array}{l}X_{1}: \text { Downstream } \\
\text { pressure }(\mathrm{kPa})\end{array}$ & $\begin{array}{l}X_{2}: \\
\text { Temperature } \\
(\mathrm{K})\end{array}$ & $\begin{array}{l}\text { Y Permeate flux J } \\
\left(\mathrm{Lm}^{-2} \mathrm{~h}^{-1}\right)\end{array}$ \\
\hline 1 & 12.5 & 338.15 & 13.791 \\
2 & 20 & 338.15 & 5.626 \\
3 & 12.5 & 338.15 & 13.315 \\
4 & 5 & 338.15 & 20.961 \\
5 & 20 & 328.15 & 1.031 \\
6 & 12.5 & 328.15 & 4.598 \\
7 & 5 & 328.15 & 14.745 \\
8 & 20 & 328.15 & 0.950 \\
9 & 20 & 338.15 & 6.894 \\
10 & 12.5 & 328.15 & 4.733 \\
11 & 5 & 328.15 & 14.138 \\
\hline
\end{tabular}

difference of the partial pressure achieved across the membrane, water migrated as vapor through the micropores and condensed in a cold trap (graduated cylinder made from glass) immersed in an ethylene glycol solution $(258.15 \mathrm{~K})$ located between the module and the vacuum pump. The pressure at the feed side of the membrane was kept constant $(10 \mathrm{kPa})$. A D-optimal plan was used for modeling and optimization. The variables that affect the performance of the VMD process include the temperature on the feed side ( 328.15 and $338.15 \mathrm{~K}$ ) and applied pressure at the permeate side of the membrane (downstream pressure; 5, 12.5 and $20 \mathrm{kPa}$ ). The VMD performance of the membrane was indicated by the permeate flux, which was determined by measuring the volume of the liquid collected in a cold trap during a certain period. After each MD experiment, the membrane was washed first with distilled water, then with a $1.0 \mathrm{M}$ sodium hydroxide solution and finally again with distilled water. The experimental design matrix as well as the obtained response is shown in Table 1 . The experimental design and analysis of data were based on a commercial statistical package, Statistica 6.0 PL (Statsoft, Inc, USA).

Evaluation of membrane filtration performance

The performance of MF, UF and MD processes was investigated by measuring a permeate flux and by analyzing the total soluble protein in permeate and retentate samples. On the basis of the data gathered, the average flux $\left(J_{\text {av }}\right)$, rejection coefficient $(R)$, volume concentration ratio (VCR) and yield $(Y)$ were determined. The average flux during concentration was calculated in accordance with the following equation (Cheryan 1998): 
$J_{\text {av }}=0.5 \times\left(J_{0}+J_{f}\right)$

where $J_{0}$ is the flux at VCR equal 1 and $J_{f}$ is the flux at the highest concentration factor.

Rejection at any point in the process was defined by:

$R=1-\frac{C_{\text {permeate }}}{C_{\text {retentate }}} \times 100 \%$

where $C_{\text {permeate }}$ and $C_{\text {retentate }}$ are the solute concentration in the permeate and retentate, respectively. The VCR was calculated based on the following equation:

$\mathrm{VCR}=\frac{V_{0}}{V_{R}}$

where $V_{O}$ and $V_{R}$ are the initial feed volume and the retentate volume, respectively.

The yield $(Y)$, which is the fraction of total soluble proteins in the original feed recovered in the final retentate, was calculated as:

$Y=\frac{C_{R} V_{R}}{C_{0} V_{0}}$

where $C_{0}$ and $C_{R}$ are the initial concentration of the component in the feed and the final retentate, whereas $V_{0}$ and $V_{R}$ are the initial volume of the feed and the final volume of the retentate, respectively. The samples obtained after concentration (permeate and retentate) were also examined for selected physicochemical parameters, and the percentage of removal was calculated.

Determination of the basic chemical composition

The samples obtained after concentration (permeate and retentate) were examined for the following physicochemical parameters: the chemical oxygen demand by means of the dichromate method (COD; PN-ISO 15705 :2005), the total organic matter extractable by petroleum ether using the gravimetric method (TOEM; PN-C-04573-01:1986), total nitrogen in accordance with the method using the flow analysis and spectrometric detection (Nitrogen; ISO 29441:2010) and total suspended solids by means of the gravimetric method (TSS; PN-EN 872:2007).

Total protein determination

The total protein concentration was analyzed with a BCA assay, using BSA as the standard. The absorbance was measured at $562 \mathrm{~nm}$ (Smith et al. 1985).

SDS-PAGE electrophoresis

Sodium dodecyl sulphate polyacrylamide gel electrophoresis (SDS-PAGE), using the Laemmli method (Laemmli
1970), was performed to analyze the proteins in the samples, using a $12 \%$ separating gel and a $5 \%$ stacking gel. Protein bands were stained with silver salts (Blum et al. 1987).

Size-exclusion chromatography

Chromatographic studies were performed with an AKTA Explorer 100 Air System (Amersham Pharmacia Biotech, Uppsala, Sweden). A HiLoad 26/60 Superdex 75 and HiLoad 26/60 Superdex 200 columns from Amersham Pharmacia Biotech (Uppsala, Sweden) were used. Assays were performed at room temperature, at a flow rate of $1 \mathrm{~mL} \min ^{-1}$. A $2.0 \mathrm{~mL}$ sample was eluted with $0.05 \mathrm{M}$ of phosphate buffer, $\mathrm{pH} 7$, containing $\mathrm{NaCl}$ at a concentration of $0.027 \mathrm{M}$. Prior to their use, the chromatographic mobile phase and all the samples before the injection into the column were filtered through a membrane filter $(0.45 \mu \mathrm{m}$, Millipore). Absorbance at $280 \mathrm{~nm}$ was used for protein detection.

\section{Results and discussion}

\section{Ultrafiltration on membranes with cutoff 3 and $30 \mathrm{kDa}$}

In the first phase of the study, proteins in the production water were separated only by means of ultrafiltration through spiral membranes with a 3 or $30 \mathrm{kDa}$ cutoff. Spiral membranes were chosen because they are most frequently used in industrial installations. When choosing molecular weight cutoff for the applied membranes, data presented by (Bourtoom et al. 2009) and (Surowiec et al. 2011) were used. It indicated that the molecular weight of most of the proteins contained in such materials exceeds $15 \mathrm{kDa}$. Thus, using this type of membranes should allow the separation of most of the proteins contained in the analyzed production water.

Experimental data confirmed the initial assumptions because the mean value of the retention coefficient of total proteins separated through membranes with a 3 and $30 \mathrm{kDa}$ cutoff was $99.96 \pm 0.012$ and $99.86 \pm 0.064 \%$, respectively. Significantly, bigger differences, i.e., of about $10 \%$ between the two analyzed membranes were observed in the case of the percentage reduction of total nitrogen (Fig. 2b). The differences result primarily from the accuracy of the analytical method used and are not statistically significant, as proved by the results of the Student's $t$ test $(p>0.05)$. However, it needs to be noted that the reduction in total proteins was higher than the reduction in total nitrogen since wastewater and permeate would contain non-protein nitrogen in the form of urates and other nitrogenous compounds of low molecular weights. Similar results were also 

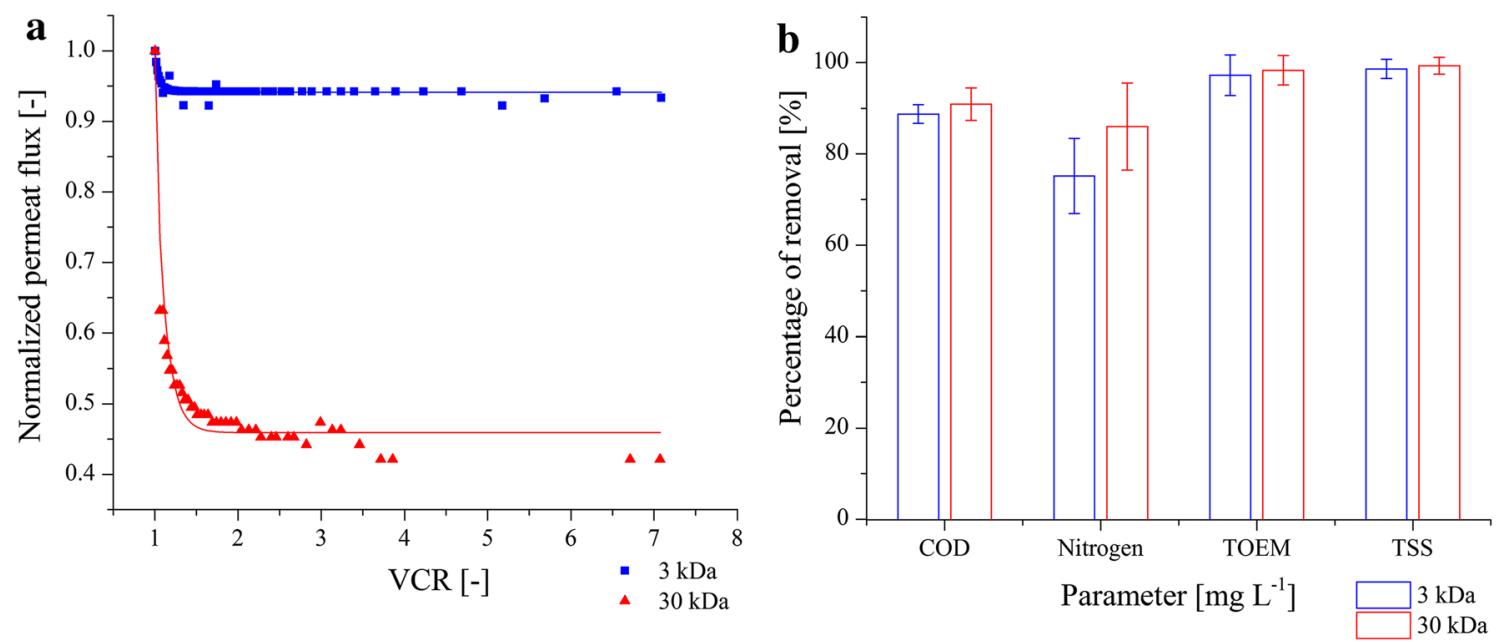

Fig. 2 Normalized permeate flux (a) and percentage of removal of COD, nitrogen, TOEM and TSS (b) during ultrafiltration of the process water on the 3 and $30 \mathrm{kDa}$ cutoff membranes. The average results of triplicate experiments with standard deviation are shown

obtained by (Shih and Kozink (1980)) using a UF membrane to treat poultry processing wastewater. These found that the reduction in true protein was $8 \%$ higher than the reduction in total nitrogen. The percentage difference in the reduction in TSS between the two membranes was $0.67 \%$ and was not statistically significant $(p>0.05)$. The permeate was clear, transparent and slightly yellowish, regardless of the membrane used. The percentage reduction in COD for the $30 \mathrm{kDa}$ cutoff membrane was $90.93 \pm 1.8 \%$, whereas the reduction in COD for the $3 \mathrm{kDa}$ cutoff membrane was $88.87 \pm 1.08 \%$ (Fig. 2b). Likewise, with regard to TSS and total nitrogen, the differences in COD between the analyzed membranes were not statistically significant $(p>0.05)$. The data on the differences in the level of COD after using UF membranes are close to the results presented by Shih and Kozink (1980) and Nelson (2006). In both studies, COD reduction was over $95 \%$. However, the data are different from that presented by Lo et al. (2005), who shows that using a $30 \mathrm{kDa}$ cutoff UF membrane made of polysulfone (PES) allows COD to be reduced by nearly $59 \%$. The remaining COD in permeate was equal to $350 \mathrm{mg} \mathrm{L}^{-1}$ and was still above the generally recognized safe direct discharge limit (200 $\mathrm{mg} \mathrm{L}^{-1}$ ). This is due to the fact that in the cited study, ultrafiltration was applied to the wastewater obtained after pretreatment with dissolved air flotation (DAF). Residuals of flocculants, detergents and disinfectants used during pretreatment were probably responsible for the high COD values of UF permeate. It is worth pointing out that the our approach, which does not include preliminary treatment of the production water with the use of chemical substances such as coagulants and flocculants, allows a protein concentrate that can be used in various ways. Theoretically, a protein concentrate may be added to the MRPM fraction, improving the overall effectiveness of the MRPM production process and increasing its nutritional value. This is mainly due to the fact that their amino acid composition is similar to that of soybean meal because they contain considerable amounts of methionine, valine, leucine, phenylalanine, and histidine (Avula et al. 2009). This solution was tested in the production of surimi (Lin et al. 1995). It was found that a $10 \%$ addition of a retentate containing concentrated sarcoplasmic and myofibril proteins does not influence the quality of the product. Moreover, a protein concentrate may also be used in the production of pet food and protein hydrolysates rich in bioactive peptides with antimicrobial properties (Martín-Sánchez et al. 2009). The relatively high fat content makes it possible to use the retentate fraction in the production of algae-based biofuels, biogas and biodiesel (Toldrá et al. 2012; Martín-Sánchez et al. 2009).

Unfortunately, irrespective of the potentially high use value of the protein concentrate, the permeate presented a significantly excessive level of COD to be removed to the sewage system without further treatment stages, as in Lo et al. (2005). In the case of both the UF membranes used, the level of COD in the permeate exceeded $2,500 \mathrm{mg} \mathrm{L}^{-1}$. This was most likely caused by a significantly higher content of protein and other substances in the process water used. The initial level of COD in the feed was $22,720 \pm 1,217 \mathrm{mg} \mathrm{L}^{-1}$, which was over 25 times higher than the COD level in the raw material used by Lo et al. (2005). Another problem that limits the possibility of direct use of ultrafiltration for process water treatment is the considerable decrease in the permeate flux. This pertained particularly to the $30 \mathrm{kDa}$ cutoff membrane, where the permeate flux at VCR $=7$ stood about $44 \%$ of its initial value (Fig. 2a). The second of the membranes analyzed, 
whose cutoff point was 10 times lower, performed in a very different way because the relative value of the permeate flux remained at the level of $94 \%$ (Fig. 2a). According to Baker (2012), the use of membranes with a high cutoff that provide for a high permeate flux is only seemingly beneficial. In many cases, these membranes are subject to irreversible fouling related to the accumulation of separated molecules inside their pores. Using membranes with a significantly lower cutoff allows internal fouling to be limited, whereas a slight decrease in the permeate flux is related to the accumulation of separated molecules on the surface of the membrane. Theoretically, according to the data presented in Fig. 2a, a membrane with a $3 \mathrm{kDa}$ cutoff should be used during the second phase of the research. However, the ability to separate proteins was not the only factor taken into account when choosing the membrane. The average permeate flux, $J_{\mathrm{av}}$, was also taken into consideration. Regardless of the phenomenon of fouling, its value for the $30 \mathrm{kDa}$ membrane amounted to approximately $0.015 \mathrm{~m}^{3} \mathrm{~m}^{-2} \mathrm{~h}^{-1}$ and it was two times higher than the value obtained for the $3 \mathrm{kDa}$ membrane. This means that the same level of concentration enables a doubling of the effectiveness per unit area of the membrane, which significantly decreases investment costs.

\section{Integrated treatment of process wastewater} by MF, UF and MD

Given the very high initial TSS content and COD in the process water, an integrated process, comprising MF, UF and VMD, was used during the second stage of the research. Microfiltration membranes for the second part of the study were chosen according to their surface properties and resistance to physical and chemical factors. It was assumed that the highly hydrophilic nature of the membrane surface would limit the protein absorption process to a minimum, which in turn would limit the risk of fouling. However, even with this type of membrane, there was still a decrease in the permeate flux, visible particularly in the first phase of the process, where VCR $<2$ (Fig. 3a). As a result, there was a $72 \%$ reduction in the permeate flux level at $\mathrm{VCR}=11$. Moreover, the decrease in the permeate flux was negatively correlated with the value of the total protein retention coefficient. At the beginning of the process, the value of this parameter was about $90 \%$, whereas at the end it reached $98 \%$ (Fig. 3a). Such a high level of protein retention in the retentate suggests that a filter cake formed on the surface of the membrane. It constituted a secondary membrane, which hindered transport of proteins across the membrane used. Similar correlations were observed by Levesley and Hoare (1999) during their research on alcohol dehydrogenase separation from homogenates of yeast cells by means of microfiltration. To increase the level of enzyme transmission, they needed to use pulsatory backflushing. As a result, they obtained a nearly fivefold increase in the value of this parameter. The efficiency of the procedures used increased along with the decrease in the concentration of suspended solids in the feed. Thus, it seems justified to state that the porosity level of the cake formed at the membrane surface during the filtration has a key influence on the transmission of the proteins. However, in the case of suspensions with a high content of soluble substances and small concentration of suspended solids, it should be assumed that fouling will be the dominating phenomenon limiting protein transport. Studies conducted with model suspensions of proteins such as BSA, ovalbumin and lysozyme showed that protein aggregates adsorb both outside and within the microfiltration membrane pores during filtration. The observed gradual decrease in membrane permeability results from chemical bonding of native protein molecules to the aggregates adsorbed to the membrane surface. The bonding is usually a disulfide covalent bond, although it is assumed that aggregate formation is also to a certain degree determined by weak van der Waals force, electrostatic and hydrophobic interactions, as well as hydrogen bonds (Marshall et al. 1997; Güell et al. 1999). The results seem to be consistent with the literature data, especially in the light of the fact that the microfiltration membrane used allowed a reduction in TSS of over $93 \%$ (Fig. 3b). The filtration cake on the surface, due to its specific composition (proteins, fats and connective tissue residue), was probably a perfect base for protein binding. It is worth emphasizing that the use of microfiltration led to a decrease in both total protein content and the COD and TOEM values, as well as total nitrogen content (Fig. 3b).

The permeate obtained was not in-line with the norms regarding permissible contamination, which was also the case in the first phase of the study, during which only UF was used. The COD value was fifty times higher than the acceptable limits. For that reason, in the subsequent phase of the study, ultrafiltration was used with the $30 \mathrm{kDa}$ cutoff membrane. According to the data presented in Fig. 3a, the decrease in the permeate flux during ultrafiltration of the process water on the $30 \mathrm{kDa}$ membrane, preceded by microfiltration, amounted to approximately $20 \%$ of the initial value. This means that the permeate flux almost doubled in comparison with the results obtained during the first phase of the study, where the preliminary treatment by microfiltration was not used. It is worth mentioning that these results were obtained with a 1.5 times higher concentration because VCR amounted to 10.3. The retention coefficient of the total proteins $\mathrm{R}_{\mathrm{TP}}$ was characterized by a lower variability. The average value of this parameter was 0.97 , while the variability coefficient was $0.85 \%$. Given the stability of the UF membrane system and the permeate 
Fig. 3 Normalized permeate flux and retention coefficient of total proteins (a) and percentage of removal of COD, nitrogen, TOEM and TSS (b) during separation of the process water on the $0.22 \mu \mathrm{m}$ microfiltration membrane and $30 \mathrm{kDa}$ cutoff ultrafiltration membrane. The average results of triplicate experiments with standard deviation are shown

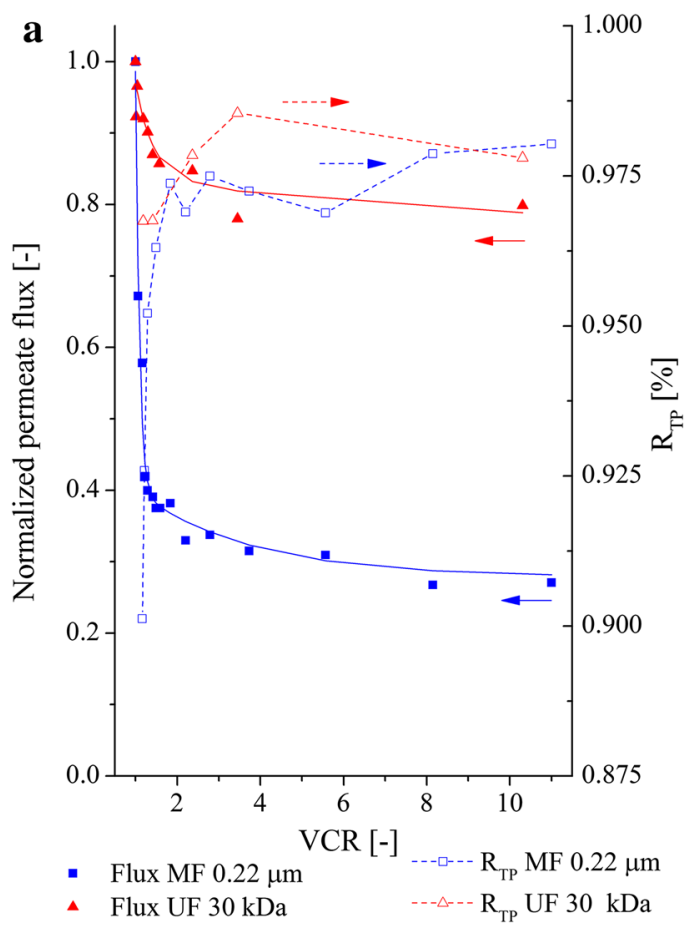

flux, preliminary treatment of the material with the use of microfiltration is fully justified. However, it is worth mentioning that using microfiltration in order to remove the insoluble particles from the suspension had a significant impact on the effectiveness of UF membranes. The most important changes were observed with regard to the values indicating the content of organic matter extractable by petroleum ether. The ability to retain these substances decreased almost twice in relation to the results obtained during the first phase of the study, where the preliminary treatment by microfiltration was not used $(p<0.001)$. This confirms the theory on the formation of filtration cake, which plays the role of a secondary membrane responsible for the decrease in permeate flux and the rate of solute transport across the membrane.

The COD value of permeate obtained during ultrafiltration repeatedly exceeded the maximum allowable limits. For that reason, in the last phase of the study, vacuum membrane distillation was used with the microporous hydrophobic membrane. This process is driven by the difference in partial pressure of the separated compounds on both sides of the membrane. Among the known types of membrane distillation such as Direct Contact Membrane Distillation (DCMD), or Sweep Gas Membrane Distillation (SGMD), Vacuum Membrane Distillation (VMD) deserve particular attention. Due to the reasonably low loss of heat related to high values of permeate flux and to the fact that heat is conducted through the membrane, this process seems to be the most energy-efficient variant of MD, which makes it a competitor to reverse osmosis. Recently, a wide range of papers have been published regarding its use in seawater desalination, thickening of sugar solutions and separation of volatile compounds (Zhao et al. 2008).

Initially, we performed an experiment aiming to determine the optimum separation conditions for obtaining maximum process efficiency expressed as a permeate flux. The experiment was performed in accordance with D-optimal plan. The results are presented in Table 1. The permeate flux, depending on the process conditions, was between 0.95 and $20.96 \mathrm{Lm}^{-2} \mathrm{~h}^{-1}$. Evaluation of the obtained data with the use of backward stepwise regression allowed the application of a regression model equation describing changes in the permeate flux, depending on the values of examined variables:

$$
\begin{aligned}
J= & -205.85-1.65 X_{1}+0.69 X_{2} \\
& +0.028 X_{1}^{2}\left(\text { Adj. } R^{2}=0.94\right)
\end{aligned}
$$

The dependent variable was both a function of pressure on the permeate side $(p<0.0001)$ and feed temperature $(p<0.0001)$. In the case of the first of the listed factors, the relationship was nonlinear, as a quadratic term was applied in the equation $(p=0.0487)$. The evaluation of absolute value of regression coefficients in this equation revealed that the $X_{1}$ factor, namely downstream pressure, had a significantly greater influence on the permeate flux. Downstream pressure was identified by various authors as the major design variable of the VMD process (Bandini et al. 1997; Sivakumar et al. 2013). Their results also revealed that the permeate flux increased by decreasing the downstream pressure. The improvement in permeate flux is 


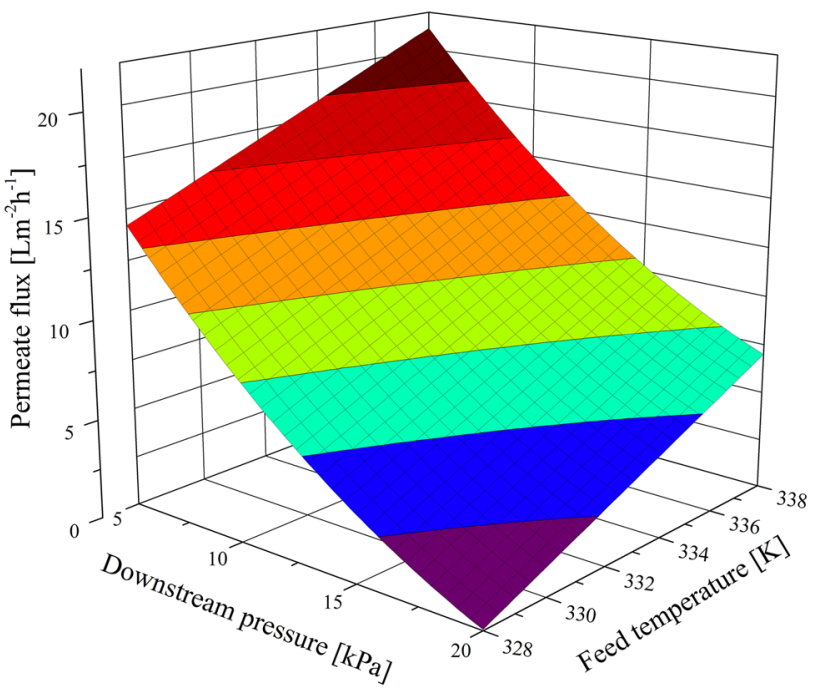

Fig. 4 Response surface for permeate flux, $J$, as function of downstream pressure and feed temperature

attributed to the fact that the mass transfer driving force, i.e., the vapor pressure difference across the membrane increased with vacuum pressure (Khayet and Matsuura 2011). More recently, Banat et al. (2003) evaluated the sensitivity of the permeate flux to the process operating parameters including downstream pressure and feed temperature. The researchers reported that the flux was more sensitive to the feed temperature at high downstream pressure levels and more sensitive to downstream pressure at low values of bulk feed temperatures. According to the experimental data presented by Banat et al. (2003), a statistically significant interaction effect between the downstream pressure and feed temperature would be expected. In the case of our results, an interaction effect between these factors is insignificant $(p>0.05)$, and hence, the response surface is flat and the corresponding contour plot contains parallel lines (Fig. 4). It may result from the fact that the experiments were conducted at a narrow temperature change range, with $\Delta T$ of $10 \mathrm{~K}$. However, despite the narrow range of temperatures investigated, the plot revealed that an increase in temperature leads to a considerable increase in the permeate flux. Our experimental results are consistent with observations made by Pangarkar et al. (2010). They reported that increasing the feed temperature results in an increase in vapor partial pressure, which in turn results in an increase in the permeate flux.

Optimization based on the data gathered confirmed that the greatest efficiency can be obtained when the process is conducted at $5.0 \mathrm{kPa}$ in $338.15 \mathrm{~K}$. In order to verify finally the correctness of the regression model adopted and the optimal parameters based on this model, a validation experiment was performed. The experimental data were compared with the predicted values determined on the basis of the regression model (Table 2). It was concluded that the permeate flux is similar to the predicted values mentioned in the model and fits within the limits determined by the $95 \%$ confidence interval. The calculations are therefore deemed correct.

During the separation process, it was also observed that the changes in the total protein concentration were directly proportional to the degree of feed concentration expressed by VCR (Fig. 5a). Pearson's correlation coefficient amounted to $r=0.984$ and was statistically significant $(p<0.0001)$. Because the analytical method applied here did not allow the protein concentration in the permeate to be determined, it was assumed that the retention coefficient was 1 . The coefficients determining the reduction rates of COD and TSS, total nitrogen and TOEM were very high, exceeding $99.9 \%$ (Fig. 5b). This means that depending on the binding legislation, the permeate obtained can be reused in the production process or used for auxiliary devices such as steam generators and cleaning systems for production installation. As far as quality is concerned, the permeate after VMD was similar to the permeate obtained using reverse osmosis.

However, it should be mentioned that during the separation process, there was a significant decrease in the permeate flux (Fig. 5a). This could be related to the increase in feed viscosity as a result of an increase in the concentration of the separated particles. As a result, there was a decrease in cross-flow velocity in the membrane module. According to Criscuoli et al. (2008), this parameter is very significant for the distillate flux because it contributes to limiting both the concentration polarization and temperature polarization. It should also be emphasized that during VMD, similarly to the remaining types of membrane distillation, the increase in the concentration of non-volatile substances present in the feed leads to a decrease in the vapor pressure of the solvent. This results in

Table 2 Validation results

\begin{tabular}{|c|c|c|c|c|c|}
\hline \multirow[t]{3}{*}{$X_{1}$ : Pressure $(\mathrm{kPa})$} & \multirow[t]{3}{*}{$X_{2}:$ Temperature $(\mathrm{K})$} & \multicolumn{4}{|c|}{ Permeate flux $\mathrm{J}\left(\mathrm{Lm}^{-2} \mathrm{~h}^{-1}\right)$} \\
\hline & & \multirow[t]{2}{*}{ Observed $\pm \mathrm{SD}$} & \multirow[t]{2}{*}{ Predicted } & \multicolumn{2}{|c|}{ Confidence interval } \\
\hline & & & & $-95 \%$ & $95 \%$ \\
\hline 5.0 & 338.15 & $21.77 \pm 0.65$ & 21.24 & 19.47 & 23.0 \\
\hline
\end{tabular}




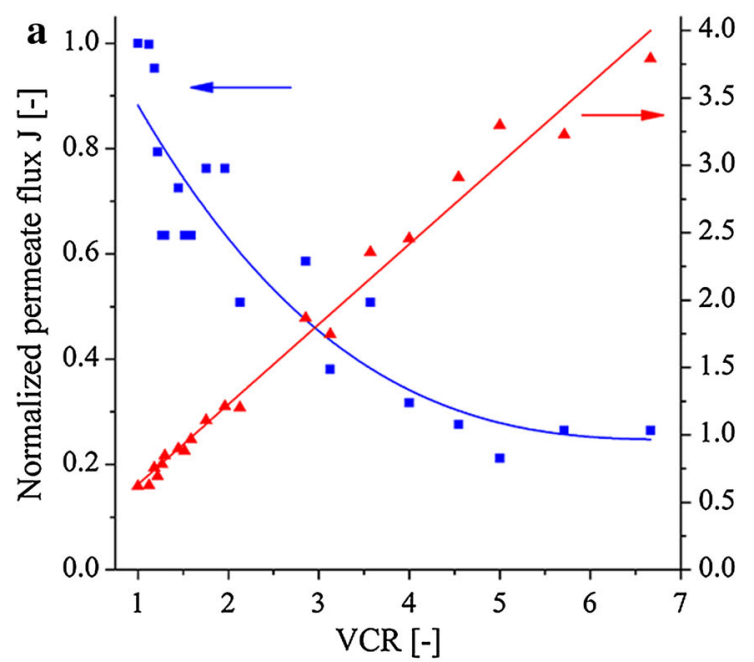

Fig. 5 Normalized permeate flux and concentration of total proteins in retentate (a) and percentage of removal of COD, nitrogen, TOEM and TSS (b) during vacuum membrane distillation (downstream

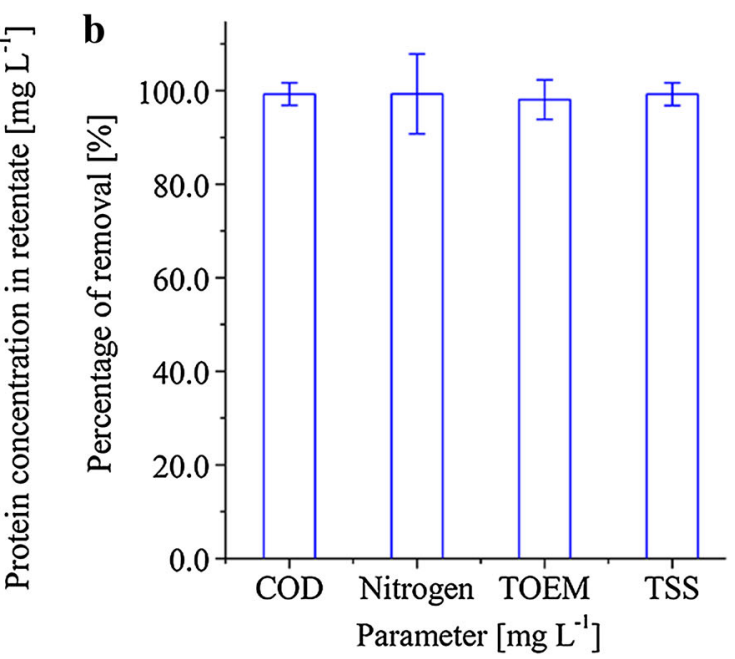

pressure $5.0 \mathrm{kPa}$, feed temperature $338.15 \mathrm{~K}$ ). The average results of triplicate experiments with standard deviation are shown

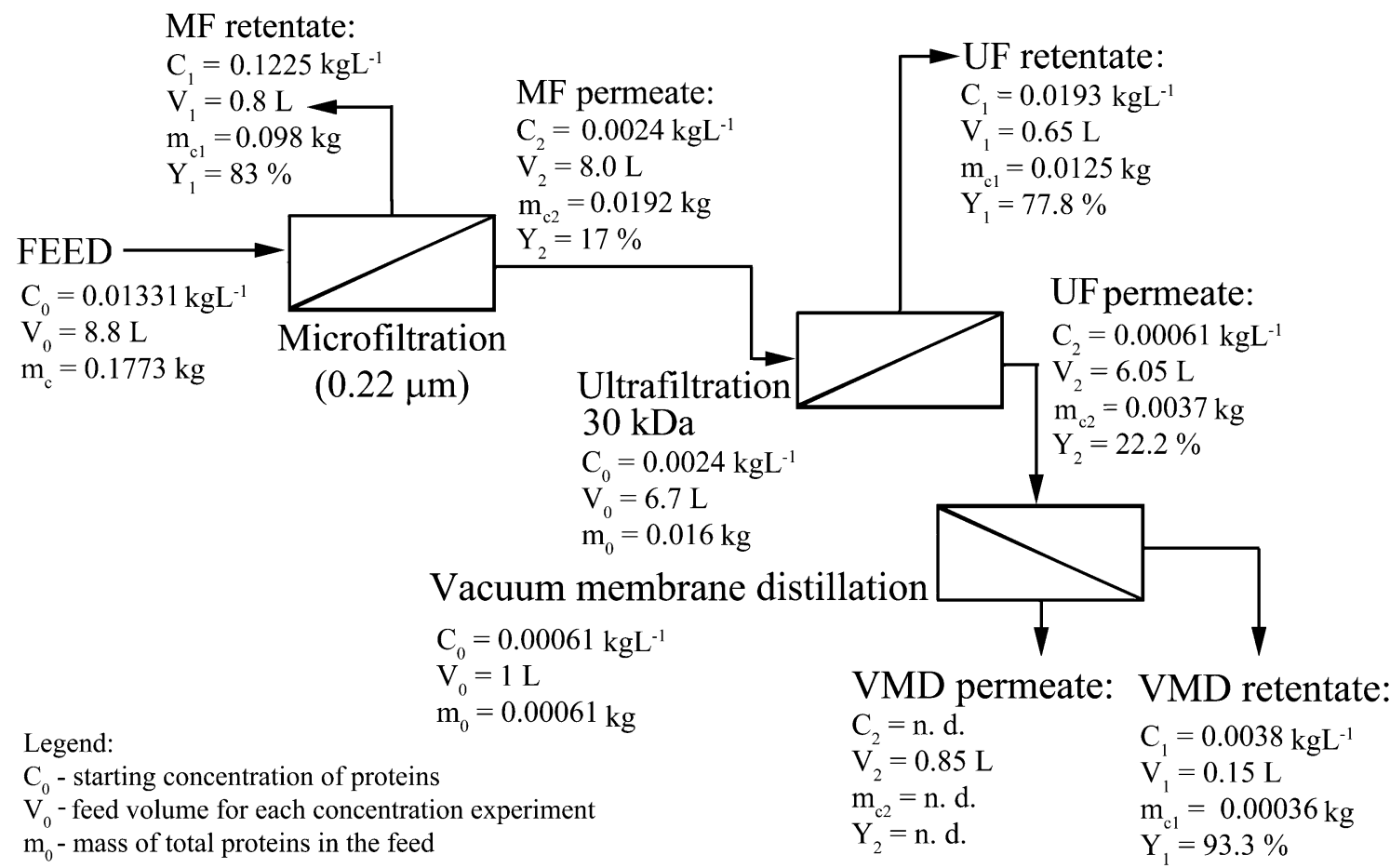

Fig. 6 Proteins mass balance for the integrated treatment of the process wastewater by MF, UF and VMD

the loss of driving force of the separation process and gradual decrease in the distillate flux (Khayet and Matsuura 2011). Fouling could also be the reason for the changes observed in the permeate flux. Fouling is related to the adsorption of the separated particles to the membrane surface. After the process, the membrane was fouled mainly with the proteins and fats, which could be judged by the change in the color of its surface from white to yellowish. According to Wang et al. (2000), polypropylene, through its hydrophobic nature, shows high protein affinity. This can be decreased by use of proper ozone modifications. When it is applied, the membrane becomes more hydrophilic, which unfortunately excludes its use in the membrane distillation process. It should be added that the process was conducted at the temperature of $383 \mathrm{~K}$, the higher temperature favored protein denaturation and 
aggregation, which additionally reinforced fouling. This seems quite probable, especially in the light of the data regarding the use of MD in the purification of solutions derived from regeneration of ion exchangers, which contain significant amounts of proteins and salt (Gryta et al. 2006). According to these authors, possible coagulation of proteins resulting from heating the solution can contribute significantly to fouling. Initial filtration of such a solution can remove the coagulated proteins, thus solving this problem.

The recovery of total soluble proteins and permeate quality assessment obtained during integrated treatment of process wastewater by MF, UF and VMD

The main objective of the presented studies was to evaluate the possibility of using membrane techniques for separating proteins contained in the effluent formed during washing MRPM and recovery of the water used during this process. The data in Fig. 6 suggest that the recovery of protein soluble in the retentate during the following phases of the process changed, starting from $83 \%$ for MF, $77 \%$ for UF and $93.3 \%$ for VMD. The total protein recovery after using the integrated process comprising MF, UF and VMD as well as the average degree of concentration amounted to, respectively, $84 \%$ and 9.3. In the case of the last of the mentioned processes, practically, the entire protein contained in the feed (permeate after UF) should be recovered in the retentate. However, it turned out that during VMD, loss amounting to $6.7 \%$ was observed. The observed differences in relation to the expected value can be a result of adsorption of proteins to the membrane surface and denaturation of the proteins as a result of high temperature, which as a consequence, was the cause of lower values of protein content during the analysis based on the BCA method.

To ultimately confirm the purity of the permeate obtained from VMD, SDS-PAGE and chromatographic analyses were conducted. They were also applied to the permeates after MF and UF. As shown in Figs. 7 and 8, MF removed proteins whose molecular weight exceeded $66 \mathrm{kDa}$ from the process water. Ultrafiltration, on the other hand, removed most of the proteins, leaving only a fraction with molecular weight only slightly exceeding $20 \mathrm{kDa}$. Both techniques clearly showed that the permeate after VMD did not contain proteins, which with nearly $100 \%$ reduction in the levels of COD, TOEM and TSS points to a very high level of process water purification, similar to RO.

The integrated process comprising MF, UF and VMD made it possible to recover $70 \%$ of the water (Fig. 6). The payment for $1 \mathrm{~m}^{3}$ of sewage discharged to sewage treatment plants in Poland stands at about $€ 1.55$, while the permissible COD level is at $1,800 \mathrm{mg} \mathrm{L}^{-1}$. Therefore, assuming that a production plant uses, e.g., about $10,000 \mathrm{~m}^{3}$ of water a month to produce surimi-like

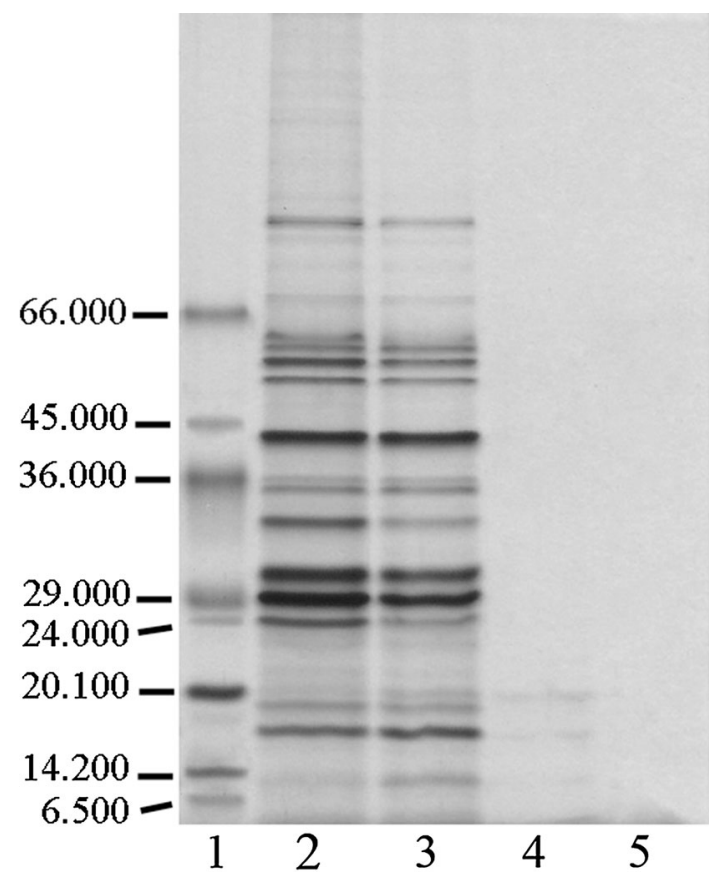

Fig. 7 SDS-PAGE analysis of samples obtained during integrated treatment of process wastewater by MF, UF and VMD. Line 1 protein molecular weight marker, Line 2 process water, Line 3 permeate obtained after MF on $0.22 \mu \mathrm{m}$ membrane, Line 4 permeate obtained after UF on $30 \mathrm{kDa}$ cutoff membrane, Line 5 permeate obtained after VMD

material from MRPM, the cost of the sewage will amount to about $€ 15,500$. It is worth stressing that process water will have to be initially purified before it is discharged to a sewage treatment plant, as its initial COD level is, as was mentioned before, at a level of $22720 \mathrm{mg} \mathrm{L}^{-1}$. In the case of production plants that are not equipped with membrane installations, it entails additional costs for the use of alternative solutions such as DAF-flocculation. Purification with the use of an integrated process (MF, UF, VMD), if $70 \%$ of water is recovered, should yield savings of $€$ 10,850 a month resulting from the reuse of water. In addition, the use of clean water will decrease by $7,000 \mathrm{~m}^{3}$ month $^{-1}$. The resultant savings, taking into account the current price of $€ 0.88$ per $\mathrm{m}^{3}$, will amount to $€$ 6,166 a month. One other product that plants will be able to use is, of course, protein. Assuming that $84 \%$ of protein is recovered, the amount of protein should be 111 tons month $^{-1}$ (Fig. 6). This protein may be used to produce pet food, which will generate $€ 33,000$ a month, assuming that the price of this product stays at $€ 300 /$ ton. Unfortunately, these data do not take into account the cost of the recovery of $1 \mathrm{~m}^{3}$ of water from the product using the suggested membrane techniques. In this study, we did not estimate them because the VMD installation which was used in our study was not equipped with in a heat recovery system, which makes it difficult to compare the data obtained with 
Fig. 8 Size Exclusion Chromatography of samples obtained during integrated treatment of process wastewater by $\mathrm{MF}$ on $0.22 \mu \mathrm{m}$ membrane, UF on $30 \mathrm{kDa}$ cutoff membrane and VMD

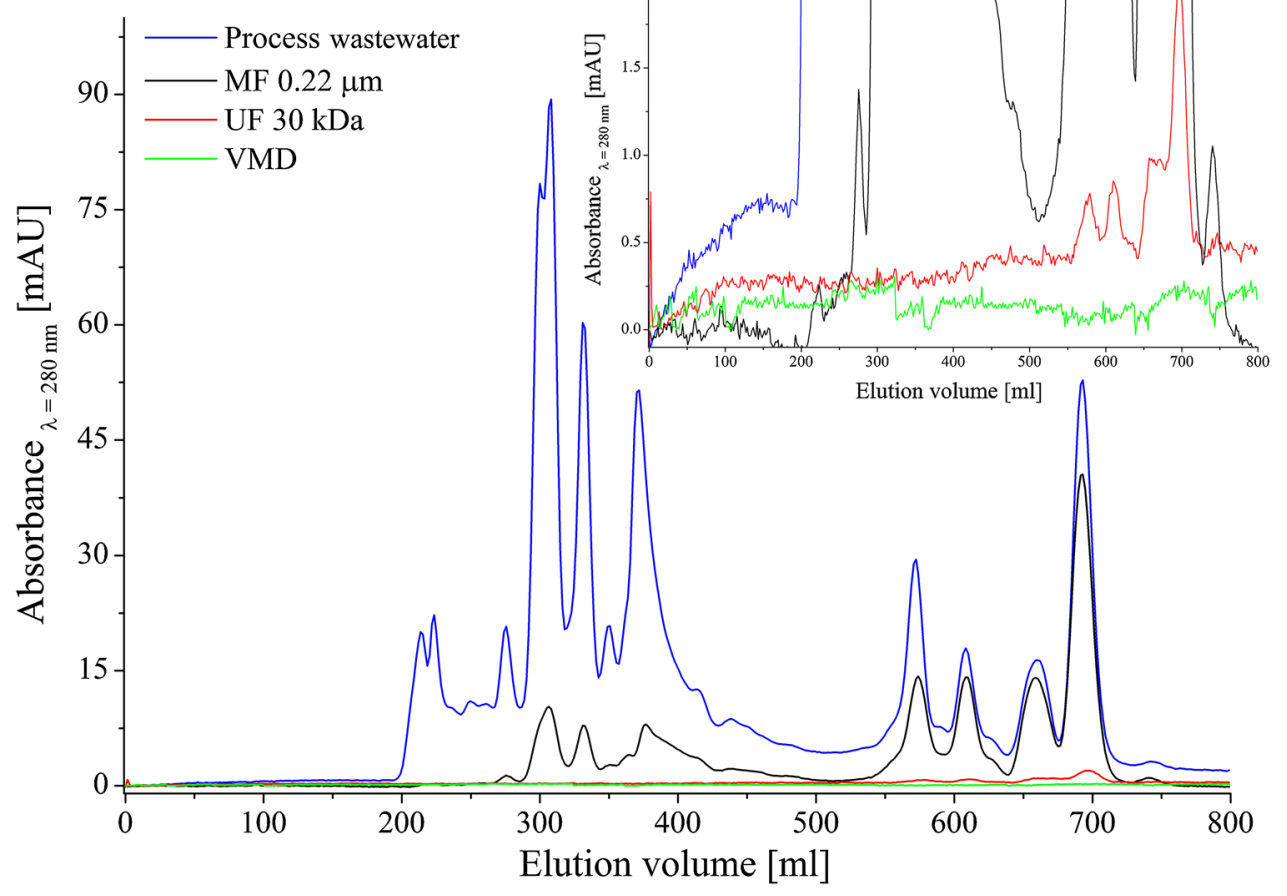

the data from industrial RO installations more often equipped with energy recovery systems (Peñate and García-Rodríguez 2012). So far, the vast majority of studies have focused on estimating water desalination costs (Zhao et al. 2013). Based on this data, it can be concluded that VMD can compete with RO on condition that waste heat from other industrial processes, solar energy or thermal energy is used. Lack of limitations related to osmotic pressure characteristic for RO is an important advantage of VMD. It opens up new perspectives for applying integrated processes, where VMD will allow significant reductions in the process costs at a high concentration degree, often unattainable for RO.

\section{Conclusion}

According to experimental data presented in this study, membrane techniques can be used successfully for the purification of process water obtained in the course of MRPM production. However, an integrated process is required in order to reduce the level of contamination, which in turn, would allow the water to be removed to the sewage system or reused in production. The solution proposed here, involving MF, UF and VMD, enables an almost ninefold reduction in the volume of waste generated and creates the possibility of obtaining a protein concentrate that might possibly be used for feed and food production. Theoretically, both proteins and recovered water, given their proper management, can be conducive to substantial savings and thus increase profits from production. VMD, which is the last phase of the process, can easily compete with generally used reverse osmosis, both in terms of the quantity and quality of the permeate.

Acknowledgment Assistance in chemical analysis of wastewater samples by the Department of Water and Soil Analysis, Faculty of Chemistry, Adam Mickiewicz University in Poznan/Poland are gratefully acknowledged.

\section{References}

Adams MC, Zulewska J, Barbano DM (2013) Effect of annatto addition and bleaching treatments on ultrafiltration flux during production of $80 \%$ whey protein concentrate and $80 \%$ serum protein concentrate. J Dairy Sci 96(4):2035-2047

Afonso MD, Bórquez R (2002) Review of the treatment of seafood processing wastewaters and recovery of proteins therein by membrane separation processes - prospects of the ultrafiltration of wastewaters from the fish meal industry. Desalination 142(1):29-45

Alan I, John L, Michael TM (2005) Waste management and byproduct utilization. In: Park JW (ed) Surimi and surimi seafood, 2nd ed. Food science and technology. CRC Press, Boca Raton, pp 279-323

Avula RY, Nelson HM, Singh RK (2009) Recycling of poultry process wastewater by ultrafiltration. Innov Food Sci Emerg Technol 10(1):1-8

Baker RW (2012) Ultrafiltration. In: Baker RW (ed) Membrane technology and applications. Wiley, New York, pp 253-302

Banat F, Al-Rub FA, Bani-Melhem K (2003) Desalination by vacuum membrane distillation: sensitivity analysis. Sep Purif Technol 33(1):75-87

Bandini S, Saavedra A, Sarti GC (1997) Vacuum membrane distillation: experiments and modeling. AIChE J 43(2):398-408 
Blum H, Beier H, Gross HJ (1987) Improved silver staining of plant proteins, RNA and DNA in polyacrylamide gels. Electrophoresis 8(2):93-99

Bohdziewicz J, Sroka E (2005) Treatment of wastewater from the meat industry applying integrated membrane systems. Process Biochem 40(3-4):1339-1346

Bourtoom T, Chinnan MS, Jantawat P, Sanguandeekul R (2009) Recovery and characterization of proteins precipitated from surimi wash-water. LWT Food Sci Technol 42(2):599-605

Cassini AS, Tessaro IC, Marczak LDF, Pertile C (2010) Ultrafiltration of wastewater from isolated soy protein production: a comparison of three UF membranes. J Clean Prod 18(3):260-265

Cheryan M (1998) Ultrafiltration and microfiltration handbook. Technomic Publishing Co, Inc., Lancaster, Pennsylvania, USA

Criscuoli A, Carnevale MC, Drioli E (2008) Evaluation of energy requirements in membrane distillation. Chem Eng Process: Process Intensif 47(7):1098-1105

Diná Afonso M, Ferrer J, Bórquez R (2004) An economic assessment of proteins recovery from fish meal effluents by ultrafiltration. Trends Food Sci Technol 15(10):506-512

Duclos-Orsello C, Li W, Ho C-C (2006) A three mechanism model to describe fouling of microfiltration membranes. J Membrane Sci 280(1-2):856-866

Dumay J, Radier S, Barnathan G, Berge JP, Jaouen P (2008) Recovery of valuable soluble compounds from washing waters generated during small fatty pelagic surimi processing by membrane processes. Environ Technol 29(4):451-461

El-Abbassi A, Kiai H, Hafidi A, García-Payo MC, Khayet M (2012) Treatment of olive mill wastewater by membrane distillation using polytetrafluoroethylene membranes. Sep Purif Technol 98:55-61

Froning GW, Mckee SR (2001) Mechanical separation of poultry meat and its use in products. In: Sams AR (ed) Poultry meat processing, CRC, Washington, DC, pp 243-256

Geetha Devi M, Shinoon Al-Hashmi ZS, Chandra Sekhar G (2012) Treatment of vegetable oil mill effluent using crab shell chitosan as adsorbent. Int J Environ Sci Technol 9(4):713-718

Gryta M, Tomaszewska M, Karakulski K (2006) Wastewater treatment by membrane distillation. Desalination 198(1-3):67-73

Güell C, Czekaj P, Davis RH (1999) Microfiltration of protein mixtures and the effects of yeast on membrane fouling. J Membrane Sci 155(1):113-122

Hausmann A, Sanciolo P, Vasiljevic T, Kulozik U, Duke M (2014) Performance assessment of membrane distillation for skim milk and whey processing. J Dairy Sci 97(1):56-71

Herzberg M, Berry D, Raskin L (2010) Impact of microfiltration treatment of secondary wastewater effluent on biofouling of reverse osmosis membranes. Water Res 44(1):167-176

Hrynets Y, Omana DA, Xu Y, Betti M (2011) Comparative study on the effect of acid- and alkaline-aided extractions on mechanically separated turkey meat (MSTM): chemical characteristics of recovered proteins. Process Biochem 46(1):335-343

Jin S, Kim I, Jung H, Kim D, Choi Y, Hur S (2007) The development of sausage including meat from spent laying hen surimi. Poult Sci 86(12):2676-2684

Joe MR, Muhammad C (2000) A brief introduction to some of the practical aspects of the kosher and halal laws for the poultry industry. In: Sams AR (ed) Poultry meat processing. CRC Press, Boca Raton

Khan Y, Yamsaengsung R, Chetpattananondh P, Khongnakorn W (2014) Treatment of wastewater from biodiesel plants using microbiological reactor technology. Int J Environ Sci Technol. doi:10.1007/s13762-014-0501-7

Khayet M, Matsuura T (2011) Membrane distillation: Principles and Applications. Elsevier, Amsterdam
Kijowski J, Stangierski J, Magnuski T, Pikul J (1996) Method of obtaining myofibril concentrate. Poland Patent

Laemmli UK (1970) Cleavage of structural proteins during the assembly of the head of bacteriophage T4. Nature 227(5259):680-685

Lee C (1990) Countercurrent and continuous washing systems. In: Martin RE, Collette RL (eds) Engineered seafood including surimi. Noyes Data Corp., Park Ridge, NJ, pp 292-296

Levesley JA, Hoare M (1999) The effect of high frequency backflushing on the microfiltration of yeast homogenate suspensions for the recovery of soluble proteins. J Membrane Sci 158(1-2):29-39

Li J, Jiao S, Zhong L, Pan J, Ma Q (2013) Optimizing coagulation and flocculation process for kaolinite suspension with chitosan. Colloids Surf A 428:100-110

Lin TMJ, Jae WP (2005) Surimi. In: Park JW (ed) Surimi and surimi seafood, 2nd ed. Food Science and Technology. CRC Press, Boca Raton, pp 33-106

Lin TM, Park JW, Morrissey MT (1995) Recovered protein and reconditioned water from surimi processing waste. J Food Sci 60(1):4-9

Lo YM, Cao D, Argin-Soysal S, Wang J, Hahm T-S (2005) Recovery of protein from poultry processing wastewater using membrane ultrafiltration. Bioresour Technol 96(6):687-698

Marshall AD, Munro PA, Trägårdh G (1997) Influence of permeate flux on fouling during the microfiltration of $\beta$-lactoglobulin solutions under cross-flow conditions. J Membrane Sci 130(1-2):23-30

Martín-Sánchez AM, Navarro C, Pérez-Álvarez JA, Kuri V (2009) Alternatives for efficient and sustainable production of surimi: a review. Compr Rev Food Sci Food Saf 8(4):359-374

Mohammad A, Ng C, Lim Y, Ng G (2012) Ultrafiltration in food processing industry: review on application, membrane fouling, and fouling control. Food Bioprocess Technol 5(4):1143-1156

Nelson HM (2006) Performance of polymeric membrane systems in the treatment of poultry processing plant waste effluent. University of Georgia, Athens

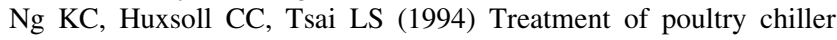
water by flocculation. J Food Process Eng 17(4):455-467

Pangarkar BL, Sane MG, Parjane SB, Abhang RM, Guddad M (2010) The heat and mass transfer phenomena in vacuum membrane distillation for desalination. Int J Chem Biol Eng 3(1):33-38

Peñate B, García-Rodríguez L (2012) Current trends and future prospects in the design of seawater reverse osmosis desalination technology. Desalination 284:1-8

Pereira AGT, Ramos EM, Teixeira JT, Cardoso GP, Ramos ADLS, Fontes PR (2011) Effects of the addition of mechanically deboned poultry meat and collagen fibers on quality characteristics of frankfurter-type sausages. Meat Sci 89(4):519-525

Piyadhammaviboon P, Yongsawatdigul J (2009) Protein cross-linking ability of sarcoplasmic proteins extracted from threadfin bream. LWT Food Sci Technol 42(1):37-43

Renault F, Sancey B, Charles J, Morin-Crini N, Badot P-M, Winterton P, Crini G (2009) Chitosan flocculation of cardboard-mill secondary biological wastewater. Chem Eng J 155(3):775-783

Shelly RM, Glenn WF (2000) Mechanical separation of poultry meat and its use in products. In: Sams AR (ed) Poultry meat processing. CRC Press, Boca Raton

Shih JCH, Kozink MB (1980) Ultrafiltration treatment of poultry processing wastewater and recovery of a nutritional by-product. Poult Sci 59(2):247-252

Sivakumar M, Ramezanianpour M, O’Halloran G (2013) Mine water treatment using a vacuum membrane distillation system. APCBEE Procedia 5:157-162 
Smith PK, Krohn RI, Hermanson GT, Mallia AK, Gartner FH, Provenzano MD, Fujimoto EK, Goeke NM, Olson BJ, Klenk DC (1985) Measurement of protein using bicinchoninic acid. Anal Biochem 150(1):76-85

Sridhar R, Sivakumar V, Prakash Maran J, Thirugnanasambandham K (2013) Influence of operating parameters on treatment of egg processing effluent by electrocoagulation process. Int J Environ Sci Technol. doi:10.1007/s13762-013-0301-5

Surowiec I, Koistinen KM, Fraser PD, Bramley PM (2011) Proteomic approach for the detection of chicken mechanically recovered meat. Meat Sci 89(2):233-237

Tezel U, Pierson JA, Pavlostathis SG (2007) Effect of polyelectrolytes and quaternary ammonium compounds on the anaerobic biological treatment of poultry processing wastewater. Water Res 41(6): 1334-1342

Tina N, Nurul H, Ruzita A (2010) Surimi-like material: challenges and prospects. Int Food Res J 17(1):509-517

Toldrá F, Aristoy MC, Mora L, Reig M (2012) Innovations in valueaddition of edible meat by-products. Meat Sci 92(3):290-296

Wang Y, Kim J-H, Choo K-H, Lee Y-S, Lee C-H (2000) Hydrophilic modification of polypropylene microfiltration membranes by ozone-induced graft polymerization. J Membrane Sci 169(2):269-276

Wibowo S, Velazquez G, Savant V, Torres JA (2005) Surimi wash water treatment for protein recovery: effect of chitosan-alginate complex concentration and treatment time on protein adsorption. Bioresour Technol 96(6):665-671

Wibowo S, Velazquez G, Savant V, Torres JA (2007) Effect of chitosan type on protein and water recovery efficiency from surimi wash water treated with chitosan-alginate complexes. Bioresour Technol 98(3):539-545

William CM (2000) Processing water and wastewater. In: Sams AR (ed) Poultry meat processing. CRC Press, Boca Raton

Wu TY, Mohammad AW, Jahim JM, Anuar N (2007) Palm oil mill effluent (POME) treatment and bioresources recovery using ultrafiltration membrane: effect of pressure on membrane fouling. Biochem Eng J 35(3):309-317

Xu L, Sheldon B, Carawan R, Larick D, Chao A (2001) Recovery and characterization of by-products from egg processing plant wastewater using coagulants. Poult Sci 80(1):57-65

Zhao Z-P, Ma F-W, Liu W-F, Liu D-Z (2008) Concentration of ginseng extracts aqueous solution by vacuum membrane distillation. 1. Effects of operating conditions. Desalination 234(1-3):152-157

Zhao K, Heinzl W, Wenzel M, Büttner S, Bollen F, Lange G, Heinzl S, Sarda N (2013) Experimental study of the memsys vacuummulti-effect-membrane-distillation (V-MEMD) module. Desalination 323:150-160 